\title{
Extremely Advanced Breast Cancer Presentation: Possible Effect of Coronavirus Pandemic Anxiety
}

\author{
GIANLUCA VANNI ${ }^{1}$, FRANCESCA SANTORI ${ }^{1}$, MARCO PELLICCIARO $^{1}$, MARCO MATERAZZO $^{1}$, \\ JONATHAN CASPI ${ }^{2}$, ALESSANDRA VITTORIA GRANAI $^{1}$, ADRIANO DE MAJO ${ }^{1}$, \\ FRANCESCA SERVADEI ${ }^{3}$, ERICA GIACOBBI ${ }^{3}$, TOMMASO PERRETTA ${ }^{4}$, ROSARIA MEUCCI $^{4}$, \\ CHIARA ADRIANA PISTOLESE ${ }^{4}$ and ORESTE CLAUDIO BUONOMO ${ }^{1}$ \\ ${ }^{1}$ Breast Unit, Department of Surgical Science, Policlinico Tor Vergata University, Rome, Italy; \\ ${ }^{2}$ Tor Vergata School of Medicine and Surgery, Policlinico Tor Vergata University, Rome, Italy; \\ ${ }^{3}$ Anatomic Pathology, Department of Experimental Medicine,Policlinico Tor Vergata University, Rome, Italy; \\ ${ }^{4}$ Department of Diagnostic Imaging and Interventional Radiology, \\ Molecular Imaging and Radiotherapy, Policlinico Tor Vergata University, Rome, Italy
}

\begin{abstract}
Background/Aim: Corona virus infection dramatically spread worldwide during 2020 and extraordinary restrictions have been implemented in order to reduce viral transmission. These measures compelled a complete restructuring of the health system, including temporary cancer screening suspension and a significant slow-down in cancer diagnoses and treatments. Case Report: We report five cases of extremely advanced breast cancer referred to our Department amid the COVID-19 pandemic. These patients exhibited a poor prognosis or worse quality of life due to their oncological disease. Conclusion: In our opinion, both the slow-down of diagnosis and treatment of oncological disease and anxiety over COVID-19 influenced this presentation. Moreover, other patients were unable to receive palliative care. Hopefully, these cases will not develop into extremely advanced-stage disease, and we will be able to provide at least the necessary palliative care.
\end{abstract}

Breast oncological disease is the most commonly diagnosed female malignancy. It is the second leading cause of cancer death among women (1). Early diagnosis is important for improving patient prognosis and guaranteeing a conservative treatment. $(2,3)$.

This article is freely accessible online.

Correspondence to: Marco Pellicciaro, MD, Breast Unit, Department of Surgical Science, PTV: Policlinico Tor Vergata University, Viale Oxford 81, 00133, Rome, Italy. Tel: +39 3280221779, e-mail: marcopell62@gmail.com

Key Words: COVID-19, advanced breast cancer, COVID-19 pandemic, breast cancer clinical presentation, lockdown.
Infection with a novel corona virus, SARS-CoV-2, dramatically spread worldwide during the 2020 (3). Due to its rapid viral transmission and high associated mortality, on March 10, 2020, the Italian government, similarly to other governments throughout the world, has implemented exceptional constraints (4-6) in order to hinder viral transmission. These necessary measures forced a complete restructuring of the health system and resource reallocation in favor of patients with Covid-19 $(7,8)$.

Amidst the pandemic, especially during the first lockdown, only urgent medical treatments were guaranteed, at the expense of diagnostic procedures and oncological therapies, which suffered significant slowdown, with crucial delays in diagnoses and treatments (9). Moreover, Covid-19related anxiety also caused further diagnostic and therapeutic delays (10), consequently increasing the number of advanced breast cancer cases (9).

Here we report five cases of patients with extremely advanced breast cancer, diagnosed during the pandemic as a possible effect of COVID-19-associated anxiety.

This work is reported following the surgical case report guidelines and written consent from all the patients was obtained.

\section{Case Report}

Case 1. A 52-year-old Caucasian woman, a former smoker of 4.75 pack years, was admitted to the Emergency Department for a lipothymic episode. Family history was negative for oncological or cardiovascular conditions and no comorbidities were reported.

Physical examination of the breast revealed an ulcerated hemorrhagic lesion on the right gland, with hard-ligneous consistency involving all the breast and extending to the 
homolateral axilla (Figure 1A). The contralateral breast presented with multiple firm cutaneous ligneous nodules (Figure 1A).

The patient underwent a contrast-enhanced total body computed tomography (CT) scan showing a breast lesion with a diameter of $17 \mathrm{~cm}$. The lesion also involved the nipple-areola complex and extended from the cutaneous plane up to the soft subfascial tissues, and to the adjacent muscular and bony structures with pathological fractures of the 3rd and 4th ribs, as well as being associated with brain, lung and liver metastases.

Moreover, bilateral axillary lymph node masses with necrosis, and internal mammary, supraclavicular and subclavicular lymph nodes suspicious for malignancy were reported. The patient underwent surgical biopsy. The pathological examination reported invasive ductal carcinoma, negative for estrogen receptor (ER) and progesterone receptor (PR), and with a Ki67 index of $15 \%$. The human epidermal growth factor receptor 2 (HER2) overexpression score was 3.

Following a multidisciplinary discussion due to the advanced disease stage (stage IV), palliative chemotherapy was planned.

At 7 months of follow-up, the patient remains alive and has had a partial response to chemotherapy.

Case 2. A 52-year-old Caucasian woman was admitted to our Unit from the Emergency Department for an ulcerated and bleeding right breast lesion (Figure 1B). The mass extended to the homolateral arm and contralateral breast. The primary lesion involved the entire homolateral axilla. The patient presented no comorbidities and had a positive family history for breast cancer. A nodule was biopsied and at pathological examination, diagnosis of infiltrating ductal breast cancer was given, with negativity for ER and PR, a Ki67 index of $15 \%$ and HER 2 overexpression score of $3+$.

The patient was scanned using positron emission tomography (PET)-CT that confirmed hypermetabolic tissue in the right breast extending from the cutaneous and subcutaneous tissues to the thoracic wall. The tumor involved both the right axillary vein and the right subclavian vein. Contralateral axillary, internal mammary, supraclavicular, subclavicular and mediastinal lymph nodes were sites of metastasis. There were also suspicious secondary lesions in the liver and lung.

Palliative chemotherapy was planned following a multidisciplinary meeting.

At 6 months of follow-up, the patient is alive, but has presented progression of their disease, including the onset of brain metastasis.

Case 3. A 65-year-old Caucasian woman was referred to our Emergency Department with fever, asthenia and weakness that had started a month before. Thoracic examination showed an ulcerated and bleeding right breast mass of about $10 \mathrm{~cm}$ in diameter and homolateral axillary lymphadenopathy (Figure 1C). Due to high clinical suspicion of advanced breast cancer, the patient underwent a mastectomy and homolateral axillary lymph node sampling.

Histological examination confirmed a parenchymal mammary site of infiltrating ductal carcinoma, grade 3 . Immunohistochemical analysis showed positivity for ER (80\%) and PR (90\%), HER2 negativity and a Ki67 index of $22 \%$. Out of six axillary lymph nodes, four were sites of breast cancer metastasis.

PET-CT scan showed hyperfixation in bones and in mediastinal, right retro-pectoral, right axillary and right paraesophageal lymph nodes.

Due to the advanced stage of the disease (stage IV; pT4bN2aM1; eighth edition of the American Joint Committee on Cancer/Union for International Cancer Control classification) (11), the patient underwent palliative chemotherapy but died from pneumonia 2 months from the beginning of chemotherapy.

Case 4. A 42-year-old Caucasian woman was referred to our Unit from the breast cancer screening program. The patient, a non-smoker, reported family history negative for oncological diseases, and no other disorders were described.

Mammography showed a cluster of microcalcifications in the lower quadrants of the left breast. Physical examination revealed the presence of a firm, deep, fixed mass of the left breast, without axillary lymphadenopathy.

At breast magnetic resonance imaging, a large infiltrative vascularized process was reported, with irregular margins. The mass extended from the retro-areolar area to the deep planes in the lower and outer quadrant of the left breast, with relation to a $1 \mathrm{~cm}$ nodule. The lesion extended for $8 \mathrm{~cm}$ lengthwise, with a rapid increase of contrast enhancement in the early phase and a subsequent rapid washout.

A core-needle biopsy of the involved breast detected a grade 3 invasive ductal carcinoma with associated ductal carcinoma in situ. Immunohistochemistry reported ER, PR, Ki67 index and HER2 as 90\%, 80\%, 30\% and 3+ overexpression, respectively.

PET-CT scan showed no other pathological increase in metabolic data beyond the already known breast mass. The patient was ultimately diagnosed with a pT3N0M0, stage IIb cancer of the left breast Neoadjuvant chemotherapy was performed after discussion by a multidisciplinary team.

The patient exhibited a complete radiological response, demonstrated by breast magnetic resonance imaging, and underwent left mastectomy and sentinel lymph node biopsy with an immediate breast reconstruction procedure, utilizing sub-pectoral tissue expander. Histological examination confirmed the complete pathological response.

At 3 months follow-up, the patient is alive, disease-free and under adjuvant chemotherapy treatment. 

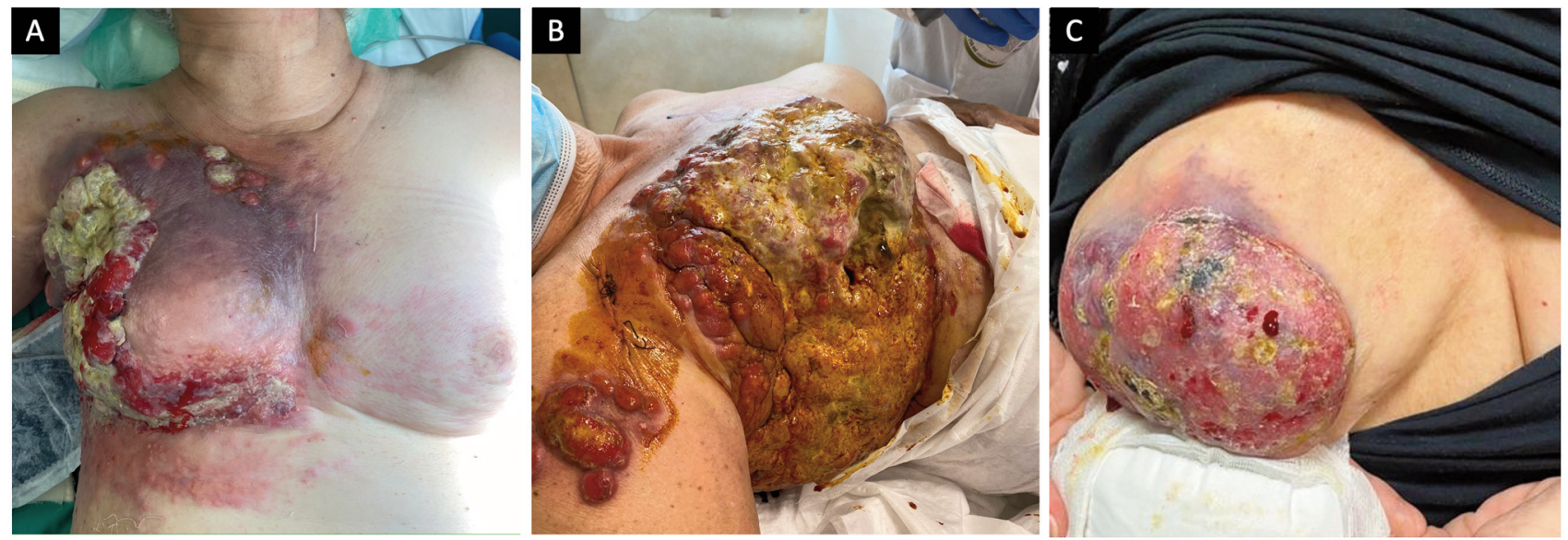

Figure 1. Patients diagnosed with extremely advanced breast cancer during the COVID-19 lockdown. A: Case 1, 49 years old. B: Case 2, 52 years old. C: Case 3, 65 years old.

Case 5. A 40-year-old African-American woman was evaluated at our Breast Unit for an ulcerated palpable mass in the left breast. Family history was positive for breast and ovarian cancer.

Breast magnetic resonance showed a massive pathological dyskaryokinetic lesion with irregular margins, polylobate, with early and persistent contrast enhancement (diameter $70 \times 45 \times 45 \mathrm{~mm}$ ) and two satellite centimetric nodules.

A biopsy of the palpable mass led to the diagnosis of a grade 3 infiltrating triple-negative ductal carcinoma with Ki67 index of $70 \%$. PET-CT scan showed hypermetabolic tissue in the left axilla and left para-sternal area. Other hypermetabolic tissues were reported in the liver and in L2 vertebra.

Following a multidisciplinary discussion, chemotherapy treatment was planned.

At 3 months of follow-up, the patient presented with disease progression.

\section{Discussion}

Breast cancer has a high incidence, corresponding to $30 \%$ of cancer diagnosed in women (12). In Italy, more than 53,000 women receive a breast cancer diagnosis every year, with an increase during recent years (12).

Breast cancer prognosis has substantially improved in terms of overall and disease-free survival (13-14), whilst invasive procedures have decreased. Both the advancement of oncological and surgical treatments, as well as a greater rate of early diagnosis facilitated this outcome improvement $(9,12,13)$. Diagnosis of breast cancer in earlier stages is a benefit largely attributed to screening programs (7-10). Early breast cancer diagnosis is a crucial factor responsible for reducing recurrence, increasing survival and improving quality of life (10). Adherence to the screening program has allowed a significant improvement in recent decades. In 2019 , out of five million women invited, $74 \%$ underwent screening mammography (7). This trend is on the increase thanks to health policies and information campaigns (7).

Since March 10, 2020, the Italian government, like other governments, has taken unprecedented action in order to limit the transmission of SARS-CoV-2 (8). The health system, due to the state of emergency, underwent complete reorganization with consequent resource reallocation in favor of patients with COVID-19 (8).

During the pandemic, only urgent procedures were guaranteed, while non-urgent treatments such as oncological procedures have suffered a substantial slow-down (9), with most oncological preventative activities being deferred, with possible effect on cancer staging.

Recommendations and strategies aiming to avoid suspension of breast cancer screening and the consequential delay in breast cancer treatments while preserving resources for patients with COVID-19 and minimizing the crossinfection risk were published by many research group and oncological society committees $(3,4,15-16)$. We reported in a previous study on the first effects of the pandemic on clinical staging, with increased diagnosis of lymph node involvement among patients with breast cancer as a possible effect of COVID-19 lockdown $(9,17,18)$.

Additionally, pandemic-associated anxiety harms quality of life and many patients may decide not to seek treatment in order to avoid hospitalization (19). All our patients referred COVID-19 anxiety as the primary reason for delayed consultation. Furthermore, higher rates of procedure and oncological treatment refusal among patients with breast 
cancer have been reported during the pandemic (10). Many patients with palpable lesions or with extremely advanced breast cancer could not be diagnosed (19, 20). These patients, having a poor prognosis, were unable to receive palliative care. This might strongly impact the quality of life of terminally ill patients.

During the first and second lockdowns, we reported five cases of extremely advanced breast cancer presented as ulcerated or bleeding breast lesions. Despite the fact the pandemic has absorbed much of the public health resources (7-9), it is our opinion that suspension of breast cancer screening and delay in breast cancer treatments were not the cause of this extremely advanced clinical presentation. Anxiety plays a fundamental role in patients, and COVID19 fear has increased the rate of hospital admission refusal with possible impact on diagnosis and palliative cure access.

We hope to be able to provide necessary palliative care and to prevent COVID-19 anxiety, whilst continuing to inform the population about the importance of breast cancer screening and follow-up even during this pandemic.

\section{Conflicts of Interest}

All Authors declare no conflicts of interest regarding this study.

\section{Authors' Contributions}

Gianluca Vanni, and Marco Pellicciaro: Conceptualization, methodology and review. Francesca Santori and Marco Pellicciaro: Writing original draft. Gianluca Vanni, Jonathan Caspi and Marco Pellicciaro: Review and editing. Marco Materazzo, Oreste Claudio Buonomo, Gianluca Vanni, Adriano De Majo and Alessandra Vittoria Granai: Performed surgical procedures. Tommaso Perretta, Rosaria Meucci and Chiara Adriana Pistolese: Performed radiological exam and diagnosis. Francesca Servadei and Erica Giacobbi: Performed pathological examination. Oreste Claudio Buonomo: Supervision. All the Authors reviewed and approve the final article.

\section{References}

1 DeSantis CE, Ma J, Gaudet MM, Newman LA, Miller KD, Goding Sauer A, Jemal A and Siegel RL: Breast cancer statistics, 2019. CA Cancer J Clin 69(6): 438-451, 2019. PMID: 31577379. DOI: $10.3322 /$ caac. 21583

2 Sardanelli F, Aase HS, Álvarez M, Azavedo E, Baarslag HJ, Balleyguier C, Baltzer PA, Beslagic V, Bick U, BogdanovicStojanovic D, Briediene R, Brkljacic B, Camps Herrero J, Colin C, Cornford E, Danes J, de Geer G, Esen G, Evans A, Fuchsjaeger MH, Gilbert FJ, Graf O, Hargaden G, Helbich TH, Heywang-Köbrunner SH, Ivanov V, Jónsson Á, Kuhl CK, Lisencu EC, Luczynska E, Mann RM, Marques JC, Martincich L, Mortier M, Müller-Schimpfle M, Ormandi K, Panizza P, Pediconi F, Pijnappel RM, Pinker K, Rissanen T, Rotaru N, Saguatti G, Sella T, Slobodníková J, Talk M, Taourel P, Trimboli RM, Vejborg I, Vourtsis A and Forrai G: Position paper on screening for breast cancer by the European Society of Breast Imaging (EUSOBI) and 30 national breast radiology bodies from Austria, Belgium, Bosnia and Herzegovina, Bulgaria, Croatia, Czech Republic, Denmark, Estonia, Finland, France, Germany, Greece, Hungary, Iceland, Ireland, Italy, Israel, Lithuania, Moldova, The Netherlands, Norway, Poland, Portugal, Romania, Serbia, Slovakia, Spain, Sweden, Switzerland and Turkey. Eur Radiol 27(7): 2737-2743, 2017. PMID: 27807699. DOI: 10.1007/s00330-016-4612-z

3 Ferroni P, Roselli M, Spila A, D'Alessandro R, Portarena I, Mariotti S, Palmirotta R, Buonomo O, Petrella G and Guadagni F: Serum sE-selectin levels and carcinoembryonic antigen mRNA-expressing cells in peripheral blood as prognostic factors in colorectal cancer patients. Cancer 116(12): 2913-2921, 2010. PMID: 20336782. DOI: 10.1002/cncr.25094

$4 \mathrm{Wu} \mathrm{Z}$ and McGoogan JM: Characteristics of and important lessons from the Coronavirus disease 2019 (COVID-19) outbreak in China: Summary of a report of 72314 cases from the Chinese Center for Disease Control and Prevention. JAMA 323(13): 12391242, 2020. PMID: 32091533. DOI: 10.1001/jama.2020.2648

5 Buonomo OC, Materazzo M, Pellicciaro M, Caspi J, Piccione E and Vanni G: Tor Vergata University-Hospital in the beginning of COVID-19-era: experience and recommendation for breast cancer patients. In Vivo 34(3 Suppl): 1661-1665, 2020. PMID: 32503826. DOI: 10.21873/invivo.11958

6 Vanni G, Pellicciaro M, Materazzo M, Dauri M, D'angelillo RM, Buonomo C, De Majo A, Pistolese C, Portarena I, Mauriello A, Servadei F, Giacobbi E, Chiaravalloti A and Buonomo OC: Awake breast cancer surgery: strategy in the beginning of COVID-19 emergency. Breast Cancer 28(1): 137-144, 2021. PMID: 32734327. DOI: 10.1007/s12282-020-01137-5

7 Vanni G, Pellicciaro M, Materazzo M, Bruno V, Oldani C, Pistolese CA, Buonomo C, Caspi J, Gualtieri P, Chiaravalloti A, Palombi L, Piccione E and Buonomo OC: Lockdown of breast cancer screening for COVID-19: possible scenario. In Vivo 34(5): 3047-3053, 2020. PMID: 32871851. DOI: 10.21873/ invivo.12139

8 Vanni G, Pellicciaro M, Materazzo M, Palombi L and Buonomo OC: Breast Cancer diagnosis in Coronavirus-era: alert from Italy. Front Oncol 10: 938, 2020. PMID: 32574281. DOI: 10.3389/ fonc 2020.00938

9 Ministry of Health: Covid-19 - Situazione in Italia. Available at: http://www.salute.gov.it/portale/nuovocoronavirus/dettaglioConte nutiNuovoCoronavirus.jsp?lingua=italiano\&id=5351\&area $=$ nuov oCoronavirus\&menu [Last accessed on May 5, 2021]

10 Vanni G, Tazzioli G, Pellicciaro M, Materazzo M, Paolo O, Cattadori F, Combi F, Papi S, Pistolese CA, Cotesta M, Santori F, Caspi J, Chiaravalloti A, Muscoli S, Lombardo V, Grasso A, Caggiati L, Raselli R, Palli D, Altomare V, D'Angelillo RM, Palombi L and Buonomo OC: Delay in breast cancer treatments during the first COVID-19 lockdown. A multicentric analysis of 432 patients. Anticancer Res 40(12): 7119-7125, 2020. PMID: 33288611. DOI: 10.21873/anticanres.14741

11 Gradishar WJ, Anderson BO, Abraham J, Aft R, Agnese D, Allison KH, Blair SL, Burstein HJ, Dang C, Elias AD, Giordano SH, Goetz MP, Goldstein LJ, Isakoff SJ, Krishnamurthy J, Lyons J, Marcom PK, Matro J, Mayer IA, Moran MS, Mortimer J, O'Regan RM, Patel SA, Pierce LJ, Rugo HS, Sitapati A, Smith KL, Smith ML, Soliman H, Stringer-Reasor EM, Telli ML, Ward JH, Young JS, Burns JL and Kumar R: Breast cancer, version 
3.2020, NCCN clinical practice guidelines in oncology. J Natl Compr Canc Netw 18(4): 452-478, 2020. PMID: 32259783. DOI: $10.6004 /$ jncen.2020.0016

12 Vanni G, Materazzo M, Pellicciaro M, Ingallinella S, Rho M, Santori F, Cotesta M, Caspi J, Makarova A, Pistolese CA and Buonomo OC: Breast cancer and COVID-19: The effect of fear on patients' decision-making process. In Vivo 34(3 Suppl): 16511659, 2020. PMID: 32503825. DOI: 10.21873/invivo.11957

13 Associazione Italiana Oncologia Medica: I Numeri del Cancro in Italia 2019. Available at: https://www.aiom.it/wpcontent/uploads/2019/09/2019_Numeri_Cancro-operatoriweb.pdf [Last accessed on May 4, 2021]

14 Bielli A, Bernardini R, Varvaras D, Rossi P, Di Blasi G, Petrella G, Buonomo OC, Mattei M and Orlandi A: Characterization of a new decellularized bovine pericardial biological mesh: Structural and mechanical properties. J Mech Behav Biomed Mater 78: 420426, 2018. PMID: 29223730. DOI: 10.1016/j.jmbbm.2017.12.003

15 Foca F, Mancini S, Bucchi L, Puliti D, Zappa M, Naldoni C, Falcini F, Gambino ML, Piffer S, Sanoja Gonzalez ME, Stracci F, Zorzi M, Paci E and IMPACT Working Group: Decreasing incidence of late-stage breast cancer after the introduction of organized mammography screening in Italy. Cancer 119(11): 2022-2028, 2013. PMID: 23504860. DOI: 10.1002/cncr.28014

16 Buonomo O, Granai AV, Felici A, Piccirillo R, De Liguori Carino N, Guadagni F, Polzoni M, Mariotti S, Cipriani C, Simonetti G, Cossu E, Schiaroli S, Altomare V, Cabassi A, Pernazza E, Casciani CU and Roselli M: Day-surgical management of ductal carcinoma in situ (DCIS) of the breast using wide local excision with sentinel node biopsy. Tumori 88(3): S48-S49, 2002. PMID: 12365390.
17 Orsaria P, Caredda E, Genova F, Materazzo M, Capuano I, Vanni G, Granai AV, DE Majo A, Portarena I, Sileri P, Petrella G, Palombi L and Buonomo OC: Additional nodal disease prediction in breast cancer with sentinel lymph node metastasis based on clinicopathological features. Anticancer Res 38(4): 2109-2117, 2018. PMID: 29599329. DOI: 10.21873/anticanres.12451

18 Ielpo B, Pernaute AS, Elia S, Buonomo OC, Valladares LD, Aguirre EP, Petrella G and Garcia AT: Impact of number and site of lymph node invasion on survival of adenocarcinoma of esophagogastric junction. Interact Cardiovasc Thorac Surg 10(5): 704-708, 2010. PMID: 20154347. DOI: 10.1510/icvts.2009.222778

19 Vanni G, Legramante JM, Pellicciaro M, DE Carolis G, Cotesta M, Materazzo M, Buonomo C, Farinaccio A, Santori F, Saraceno F, Ielpo B, Aiello F, Paganelli C, Grande M, DE Andreis G, Chiocchi M, Palombi L and Buonomo OC: Effect of lockdown in surgical emergency accesses: experience of a COVID-19 hospital. In Vivo 34(5): 3033-3038, 2020. PMID: 32871849. DOI: 10.21873 /invivo.12137

20 Orsaria P, Varvaras D, Vanni G, Pagnani G, Scaggiante J, Frusone F, Granai AV, Petrella G and Buonomo OC: Nodal status assessment in breast cancer: strategies of clinical grounds and quality of life implications. Int J Breast Cancer 2014: 469803, 2014. PMID: 24672730. DOI: 10.1155/2014/469803

Received April 13, 2021

Revised May 1, 2021

Accepted May 5, 2021 